Kansas State University Libraries

New Prairie Press

\title{
ANALYSIS OF MIXED MODELS WITHOUT MIXED MODELS SOFTWARE
}

George A. Milliken

Follow this and additional works at: https://newprairiepress.org/agstatconference

Part of the Agriculture Commons, and the Applied Statistics Commons

\section{(c) (i) $\ominus$}

This work is licensed under a Creative Commons Attribution-Noncommercial-No Derivative Works 4.0 License.

\section{Recommended Citation}

Milliken, George A. (1992). "ANALYSIS OF MIXED MODELS WITHOUT MIXED MODELS SOFTWARE,"

Conference on Applied Statistics in Agriculture. https://doi.org/10.4148/2475-7772.1404

This is brought to you for free and open access by the Conferences at New Prairie Press. It has been accepted for inclusion in Conference on Applied Statistics in Agriculture by an authorized administrator of New Prairie Press. For more information, please contact cads@k-state.edu. 


\title{
Analysis of Mixed Models Without Mixed Models Software
}

\author{
by \\ George A. Milliken \\ Department of Statistics \\ Kansas State University \\ Manhattan, KS 66506
}

The recent development of mixed model software has expanded the use of mixed models analysis, but mixed models have been analyzed using non-mixed models software for many years. The purpose of this paper is to discuss the differences, similarities, advantages and disadvantages of the two approaches. Section 1 introduces the mixed model with two examples. The analysis of the mixed model using mixed models software is presented in Section 2 and the analysis of the mixed model using non-mixed models software is described in Section 3. Finally, an 'example' is used to compare the two methodologies.

\section{Mixed Model}

The linear model with fixed effects can be expressed as (Graybill, 1976)

$$
\underline{Y}=\underline{X} \underline{\beta}+\underline{\epsilon}
$$

where $\underline{Y}$ is a $\mathrm{nx} 1$ vector of observations, $\underline{\beta}$ is a $\mathrm{px} 1$ vector of unknown parameters, $\underline{\mathrm{X}}$ is a nxp design matrix with known constants and $\underline{\epsilon}$ is the random error or noise vector of the model where the usual assumptions are $\underline{\epsilon} \sim \mathrm{N}\left(\underline{0}, \sigma_{\epsilon}^{2} \underline{I}_{n}\right)$. Model (1.1) contains one random component, $\underline{\epsilon}$, with one variance parameter, $\sigma_{\epsilon}^{2}$.

A mixed model is a linear model with more than one random component so there is more than one variance parameter.

Many traditional models are mixed models. A model to describe a two-way mixed effects treatment structure is a mixed model. If the levels of the row treatment $\left(\alpha_{\mathrm{i}}\right)$ are fixed and the levels of the column treatment $\left(\mathrm{t}_{\mathrm{j}}\right)$ are random, then the corresponding mixed model is

$$
\mathrm{Y}_{\mathrm{ijk}}=\mu+\alpha_{\mathrm{i}}+\mathrm{t}_{\mathrm{j}}+\mathrm{c}_{\mathrm{ij}}+\epsilon_{\mathrm{ijk}}
$$

where $\mu+\alpha_{\mathrm{i}}$ is the fixed effects part of the model and $\mathrm{t}_{\mathrm{j}}+\mathrm{c}_{\mathrm{ij}}+\epsilon_{\mathrm{ijk}}$ is the random effects part of the model with $\mathrm{t}_{\mathrm{j}} \sim$ iid $\mathrm{N}\left(0, \sigma_{\mathrm{t}}^{2}\right), \mathrm{c}_{\mathrm{ij}} \sim$ iid $\mathrm{N}\left(0, \sigma_{\mathrm{c}}^{2}\right)$ and $\epsilon_{\mathrm{ijk}} \sim$ iid $\mathrm{N}\left(0, \sigma_{\epsilon}^{2}\right)$. Model (1.2) has three random components or random variables, $\mathrm{t}_{\mathrm{j}}, \mathrm{c}_{\mathrm{ij}}$ and 
$\epsilon_{\mathrm{ijk}}$ and the variance of $\mathrm{Y}$ can be described by three components of variance, $\sigma_{\mathrm{t}}^{2}, \sigma_{\mathrm{c}}^{2}$ and $\sigma_{\epsilon}^{2}$.

The usual split-plot model with a two-way fixed effects treatment structure and two sizes of experimental units (whole plots and subplots) where the levels of the whole plot treatment A are randomly assigned to the whole plots (completely randomized whole plot design structure) is

$$
\mathrm{Y}_{\mathrm{ijk}}=\mu+\alpha_{\mathrm{i}}+\tau_{\mathrm{j}}+\gamma_{\mathrm{ij}}+\mathrm{e}_{\mathrm{ij}}+\epsilon_{\mathrm{ijk}}
$$

where $\mu+\alpha_{\mathrm{i}}+\tau_{\mathrm{j}}+\gamma_{\mathrm{ij}}$ is the fixed effects part of the model and $\mathrm{e}_{\mathrm{ij}}+\epsilon_{\mathrm{ijk}}$ is the random effects part of the model where $\mathrm{e}_{\mathrm{ij}}$ is the whole plot error, $\mathrm{e}_{\mathrm{ij}} \sim$ iid $\mathrm{N}\left(0, \sigma_{\mathrm{e}}^{2}\right)$, and $\epsilon_{\mathrm{ijk}}$ is the subplot error, $\epsilon_{\mathrm{ijk}} \sim$ iid $\mathrm{N}\left(0, \sigma_{\epsilon}^{2}\right)$. The whole plot part of the model is $\mu+\alpha_{\mathrm{i}}+\mathrm{e}_{\mathrm{ij}}$ and the subplot part of the model is $\tau_{\mathrm{i}}+\gamma_{\mathrm{ij}}+\epsilon_{\mathrm{ijk}}$.

The matrix representation of a mixed effects model with two random components is

$$
\underline{\mathrm{Y}}=\underline{\mathrm{X}} \underline{\beta}+\underline{\mathrm{Z}} \underline{\mathrm{a}}+\underline{\epsilon}
$$

where $\underline{X} \underline{\beta}$ is the fixed effects part as in equation (1.1), $\underline{Z} \underline{\mathrm{a}}+\underline{\epsilon}$ is the random effects part where $\underline{Z}$ is a nxt design matrix of known constants, $\underline{\mathrm{a}} \sim \mathrm{N}\left(\underline{0}, \sigma_{\mathrm{a}}^{2} \underline{\mathrm{I}}_{t}\right)$ and $\underline{\epsilon} \sim$ $\mathrm{N}\left(\underline{0}, \sigma_{\epsilon}^{2} \underline{I}_{n}\right)$. This model has two random variables, $\underline{\mathrm{a}}$ and $\underline{\epsilon}$ and two associated variance components.

Model (1.4) can be expressed as

$$
\underline{\mathrm{Y}}=\underline{\mathrm{X}} \underline{\beta}+\underline{\mathrm{e}}
$$

where

$$
\underline{\mathrm{e}} \sim \mathrm{N}\left(\underline{0}, \sigma_{\epsilon}^{2} \underline{\mathrm{I}}_{\mathrm{n}}+\sigma_{\mathrm{a}}^{2} \underline{\mathrm{Z}} \underline{\mathrm{Z}}^{\prime}\right)
$$

In model (1.5), $\underline{X} \underline{\beta}$ is the fixed effects part and $\underline{\mathrm{e}}$ is the random effects part of the model. The model indicates that

$$
\underline{\mathrm{Y}} \sim \mathrm{N}(\underline{\mathrm{X}} \underline{\beta}, \underline{\Sigma}) \text { where } \underline{\Sigma}=\sigma_{\epsilon}^{2} \underline{\mathrm{I}}+\sigma_{\mathrm{a}}^{2} \underline{\mathrm{Z}} \underline{Z}^{\prime} \text {. }
$$

Model (1.4) can be extended to $\mathrm{k}+1$ random components as

$$
\underline{Y}=\underline{X} \underline{\beta}+\underline{Z}_{1} \underline{a}_{1}+\underline{Z}_{2} \underline{\mathrm{a}}_{2}+\ldots+\underline{\mathrm{Z}}_{\mathrm{k}} \underline{\mathrm{a}}_{\mathrm{k}}+\underline{\epsilon}
$$

where $\underline{a}_{i} \sim N\left(\underline{0}, \sigma_{i}^{2} \underline{I}_{t_{i}}\right) i=1,2, \ldots, k$ 


$$
\underline{\epsilon} \sim \mathrm{N}\left(\underline{0}, \sigma_{\epsilon}^{2} \underline{I}\right)
$$

and $\underline{\mathrm{Z}}_{\mathrm{i}} \mathrm{i}=1,2, \ldots, \mathrm{k}$ are $n x t_{\mathrm{i}}$ design matrices of constants. The model corresponding to model (1.5) is

$$
\begin{gathered}
\underline{\mathrm{Y}}=\underline{\mathrm{X}} \underline{\beta}+\underline{\mathrm{e}} \text { where } \\
\underline{\mathrm{e}} \sim \mathrm{N}(\underline{0}, \underline{\Sigma}) \text { and } \\
\underline{\Sigma}=\sigma_{\epsilon}^{2} \underline{\mathrm{I}}_{\mathrm{n}}+\sigma_{1}^{2} \underline{\mathrm{Z}}_{1} \underline{\mathrm{Z}}_{1}^{\prime}+\sigma_{2}^{2} \underline{\mathrm{Z}}_{2} \underline{\mathrm{Z}}_{2}^{\prime}+\ldots+\sigma_{\mathrm{k}}^{2} \underline{\mathrm{Z}}_{\mathrm{k}} \underline{\mathrm{Z}}_{\mathrm{k}}^{\prime} .
\end{gathered}
$$

Additional structure could be added to the model in terms of correlations among the elements of a random effect. For example, in a repeated measures design one might assume $\underline{\epsilon} \sim \mathrm{N}(\underline{0}, \underline{\Lambda})$ where $\Lambda$ is a covariance matrix with some structure (or it may be unstructured).

For purposes of the present discussion, a mixed model with one additional random component as in equations (1.4) through (1.6) is used to demonstrate the analyses and comparisons.

\section{Mixed Model Analysis using Mixed Model Techniques}

The mixed model analysis is carried out in two phases, the analysis of the random effects and then the analysis of the fixed effects. First, one obtains estimates of the variance components using some method as Maximum Likelihood, restricted or residual maximum likelihood, Minque or Mivque or Method of Moments such as Henderson's Method 3. Once the variance components are estimated, the covaraince matrix $\underline{\Sigma}$ is estimated as

$$
\underline{\hat{\Sigma}}=\hat{\sigma}_{\epsilon}^{2} \underline{I}_{n}+\hat{\sigma}_{\mathrm{a}}^{\mathrm{Z}} \underline{\mathrm{Z}} \underline{Z}^{\prime}
$$

The estimate of the covariance matrix must be positive definite, thus the estimates of the variance components must not be negative.

Next the mixed model equations (Henderson (1984)) are constructed as

$$
\left[\begin{array}{cc}
\frac{1}{\hat{\sigma}_{\epsilon}^{2}} \underline{X} \underline{X}^{\prime} & \frac{1}{\hat{\sigma}_{\epsilon}^{2}} \underline{X}^{\prime} \underline{Z} \\
\frac{1}{\hat{\sigma}_{\epsilon}^{2}} \underline{Z}^{\prime} \underline{X} & \frac{1}{\hat{\sigma}_{\epsilon}^{2}} \underline{Z}^{\prime} \underline{Z}+\frac{1}{\hat{\sigma}_{\mathrm{a}}^{2}} \underline{I}
\end{array}\right]\left[\begin{array}{l}
\hat{\hat{\beta}}_{\mathrm{M}} \\
\underline{\hat{\mathrm{a}}}_{\mathrm{m}}
\end{array}\right]=\left[\begin{array}{l}
\frac{1}{\hat{\sigma}_{\epsilon}^{2}} \underline{X}^{\prime} \underline{\mathrm{y}} \\
\frac{1}{\hat{\sigma}_{\epsilon}^{2}} \underline{\mathrm{Z}}^{\prime} \mathrm{y}
\end{array}\right] .
$$

The solution for $\hat{\beta}_{M}$ satisfies the equations 


$$
\underline{X}^{\prime} \underline{\hat{\Sigma}}^{-1} \underline{X}_{\hat{\beta}}=\underline{X}^{\prime} \underline{\underline{\Sigma}} y .
$$

The linear combination of $\underline{c}^{\prime} \underline{\beta}$ is estimable for model (1.4) if there exists a $\underline{b}$ such that $\underline{c}=\underline{X} \underline{b}$, that is, estimability depends only on the matrix $\underline{X}$.

For most balance designs (like a 2-way mixed model design and split-plot design) $\underline{\mathrm{X}}^{\prime} \underline{\hat{\Sigma}} \underline{\mathrm{X}}=\mathrm{f}\left(\hat{\sigma}_{\epsilon}^{2}, \hat{\sigma}_{\mathrm{a}}^{2}\right) \underline{\mathrm{X}}^{\prime} \underline{\mathrm{X}}$ and $\underline{\mathrm{X}}^{\prime} \underline{\hat{\Sigma}} \underline{\mathrm{Y}}=\mathrm{f}\left(\hat{\sigma}_{\epsilon}^{2}, \hat{\sigma}_{\mathrm{a}}^{2}\right) \underline{\mathrm{X}} \underline{\mathrm{Y}}$ where $\mathrm{f}\left(\hat{\sigma}_{\epsilon}^{2}, \hat{\sigma}_{\mathrm{a}}^{2}\right)$ is a constant. Thus the mixed model solution for $\underline{\hat{\beta}}_{M}$ satisfies $\underline{X}^{\prime} \underline{\hat{\beta}}_{M}=\underline{X}^{\prime} \underline{y}$, the same as the least squares normal equations. The asymptotic sampling distribution of the estimate of an estimable function, $\underline{\mathrm{c}^{\prime}} \underline{\beta}$ is

$$
\underline{\mathrm{c}}^{\prime} \underline{\hat{\beta}}_{\mathrm{M}} \sim \mathrm{N}\left(\underline{\underline{c}} \underline{\underline{\beta}}, \underline{\mathrm{c}}^{\prime}\left(\underline{X}^{\prime} \underline{\Sigma}^{-1} \underline{\mathrm{X}}\right)^{-} \underline{\mathrm{c}}\right)
$$

The degrees of freedom associated with the estimate of the variance of $\underline{c}^{\prime} \hat{\underline{\beta}}_{\mathrm{M}}$,

$$
\hat{\sigma}_{\underline{c}^{\prime} \underline{\hat{\beta}}}^{2}=\underline{\mathrm{c}}^{\prime}\left(\underline{X^{\prime}} \underline{\hat{\underline{N}}}^{-1} \underline{X}\right)^{-} \underline{\mathrm{c}}
$$

are approximated by $\mathrm{v}=\mathrm{n}-\operatorname{Rank}(\underline{\mathrm{X}}, \underline{\mathrm{Z}})$ or the usual error degrees of freedom. The degrees of freedom can also be approximated by using those degrees of freedom corresponding to analysis without mixed model software. A confidence interval about $\underline{c^{\prime}} \underline{\beta}$ can be constructed by $\underline{\mathrm{c}^{\prime}} \hat{\underline{\beta}} \pm\left[\mathrm{t}_{\mathrm{a} / 2, v}\right] \hat{\sigma}_{\underline{c^{\prime}} \hat{\underline{\beta}}}$.

The statistic to test a hypothesis about a set of estimable functions, e.g., $\mathrm{H}_{\mathrm{o}}$ : $\underline{\mathrm{A}} \underline{\beta}$ $=\underline{\mathrm{h}}$ vs. $\mathrm{H}_{\mathrm{a}}: \underline{\mathrm{A}} \underline{\beta} \neq \underline{\mathrm{h}}$ where $\underline{\mathrm{A}}$ and $\underline{\mathrm{h}}$ are arrays of given constants is $\mathrm{F}_{\mathrm{c}}=\mathrm{SSH}_{\mathrm{o}} / \mathrm{r}$ where

$$
\mathrm{SSH}_{\mathrm{O}}=\left(\underline{\mathrm{A}}_{\hat{\mathrm{\beta}}}^{\mathrm{M}}-\underline{\mathrm{h}}\right)^{\prime}\left[\underline{\mathrm{A}}\left(\underline{X}^{\prime} \underline{\hat{E}}^{-1} \underline{\mathrm{X}}\right)^{-} \underline{\mathrm{A}}^{\prime}\right]^{-}\left(\underline{\mathrm{A}}_{\mathrm{\beta}}{ }_{\mathrm{M}}-\underline{\mathrm{h}}\right)
$$

and $\mathrm{r}=\operatorname{Rank}(\underline{\mathrm{A}})$. The small sample approximation to the asymptotic sampling distribution of $\mathrm{F}_{\mathrm{c}}$ is $\mathrm{F}(\mathrm{r}, v)$ where $v$ is the approximate degrees of freedom associated with the appropriate error mean square. The noncentrality parameter is $\lambda=(\underline{A} \underline{\beta}$ $\underline{\mathrm{h}})^{\prime}\left(\underline{\mathrm{A}}\left(\underline{\mathrm{X}^{\prime}} \underline{\underline{E}}^{-1} \underline{\mathrm{X}}\right)^{-1} \underline{\mathrm{A}^{\prime}}\right]^{\prime}(\underline{\mathrm{A}} \underline{\beta}-\underline{\mathrm{h}})$.

\section{Mixed Model Analysis without using Mixed Model Metỉods}

The first step in this analysis is to estimate the variance components using some method as described in section 2. Next, the fixed effects part of the analysis is accomplished.

The analysis of model (1.4) without mixed software considers the model as a fixed effects model when estimating estimable functions of $\underline{\beta}$.

The model is 


$$
\underline{Y}=[\underline{X}, \underline{Z}]\left[\begin{array}{l}
\underline{\beta} \\
\underline{a}
\end{array}\right]+\underline{\epsilon}
$$

which assumes $\underline{\text { a }}$ is a fixed effect and $\underline{\epsilon}$ is the only error term.

An estimate of $\left(\underline{\beta}^{\prime}, \underline{a}^{\prime}\right)$ is a solution for $\left(\underline{\hat{\beta}}_{L}^{\prime}, \underline{\hat{a}}_{L}^{\prime}\right)$ to the system of equations

$$
\left[\begin{array}{ll}
\underline{X}^{\prime} \underline{X} & \underline{X}^{\prime} \underline{Z} \\
\underline{Z^{\prime}} \underline{X} & \underline{Z}^{\prime} \underline{Z}
\end{array}\right]\left[\begin{array}{l}
\underline{\hat{\beta}}_{L} \\
\underline{\hat{a}}_{L}
\end{array}\right]=\left[\begin{array}{l}
\underline{X}^{\prime} \underline{ } \\
\underline{Z}^{\prime} \underline{y}
\end{array}\right]
$$

For model (3.1), a linear combination of $\underline{\beta}, \underline{c} \underline{\beta}$ is estimable if there is a $\underline{b}$ such that $\left[\begin{array}{l}\underline{\mathrm{c}} \\ \underline{0}\end{array}\right]=\left[\begin{array}{l}\mathrm{X}^{\prime} \\ \mathrm{Z}^{\prime}\end{array}\right] \underline{\mathrm{b}}$. A major draw back of this analysis is the estimability of $\underline{\mathrm{c}^{\prime}} \underline{\underline{\beta}}$ depends on both $\underline{X}$ and $\underline{Z}$, not just $\underline{X}$ as in the mixed model analysis of section 2 . The estimate of an estimable function of $\underline{\beta}, \underline{c^{\prime}} \underline{\beta}$, is

$$
\underline{c}^{\prime} \underline{\beta}_{\mathrm{L}}=\left(\underline{\mathrm{c}}^{\prime}, \underline{0^{\prime}}\right)\left[\begin{array}{ll}
\underline{\mathrm{X}}^{\prime} \underline{\mathrm{X}} & \underline{\mathrm{X}^{\prime}} \underline{\mathrm{Z}} \\
\underline{\mathrm{Z}^{\prime}} \underline{\mathrm{X}} & \underline{\mathrm{Z}^{\prime}} \underline{\mathrm{Z}}
\end{array}\right]^{-}\left[\begin{array}{l}
\underline{\mathrm{X}}^{\prime} \\
\underline{\mathrm{Z}}^{\prime}
\end{array}\right] \mathrm{y} .
$$

The variance of the estimator in (3.3) is

$$
\operatorname{Var}\left(\underline{\mathrm{c}}^{1} \hat{\underline{\beta}}_{\mathrm{L}}\right)=\left(\underline{\mathrm{c}}^{\prime}, \underline{0^{\prime}}\right)\left[\begin{array}{ll}
\underline{\mathrm{X}} \underline{\mathrm{X}} & \underline{\mathrm{X}^{\prime}} \underline{\mathrm{Z}} \\
\underline{Z^{\prime}} \underline{\mathrm{X}} & \underline{Z^{\prime}} \underline{Z}
\end{array}\right]^{-}\left[\begin{array}{l}
\underline{X}^{\prime} \\
\underline{Z}^{\prime}
\end{array}\right] \underline{\Sigma}[\underline{X}, \underline{Z}]\left[\begin{array}{ll}
\underline{X^{\prime}} \underline{X} & \underline{X^{\prime}} \underline{Z} \\
\underline{Z^{\prime}} \underline{X} & \underline{Z^{\prime}} \underline{Z}
\end{array}\right]^{-}\left[\begin{array}{l}
\underline{\mathrm{c}} \\
\underline{0}
\end{array}\right]
$$

which is a linear function of the variance components as

$$
\operatorname{Var}\left(\underline{c^{\prime} \hat{\beta}}\right)=\mathrm{b}_{1} \sigma_{\epsilon}^{2}+\mathrm{b}_{2} \sigma_{\mathrm{a}}^{2}=\mathrm{b}_{1}\left(\sigma_{\epsilon}^{2}+\frac{\mathrm{b}_{2}}{\mathrm{~b}_{1}} \sigma_{\mathrm{a}}^{2}\right)
$$

where $b_{1}$ and $b_{2}$ are constants depending on $\underline{c}, \underline{X}$ and $\underline{Z}$.

If one assumes model (3.1) is a fixed effects model only, then the variance of $\underline{c}^{\prime} \hat{\beta}_{L}$ is 


$$
\begin{aligned}
\operatorname{Var}\left(\underline{\mathrm{c}}^{\prime} \underline{\hat{\beta}}_{\mathrm{L}}\right)_{\mathrm{F}} & =\sigma_{\epsilon}^{2}\left(\underline{\mathrm{c}}^{\prime}, \underline{0^{\prime}}\right)\left[\begin{array}{ll}
\underline{\mathrm{X}^{\prime}} \underline{\mathrm{X}} & \underline{\mathrm{X}^{\prime}} \underline{\mathrm{Z}} \\
\underline{\mathrm{Z}^{\prime}} \underline{\mathrm{X}} & \underline{Z^{\prime}} \underline{\mathrm{Z}}
\end{array}\right]^{-}\left(\begin{array}{l}
\underline{\mathrm{c}} \\
\underline{0}
\end{array}\right) \\
& =\mathrm{b}_{1} \sigma_{\epsilon}^{2} .
\end{aligned}
$$

Non-mixed models software such as PROC GLM of the SAS ${ }^{\circledR}$ system (SAS Institute 1990) can provide the estimate of $\operatorname{Var}\left(\underline{c}^{\prime} \hat{\beta}_{L}\right)_{F}$ as

$$
\operatorname{Var}\left(\mathrm{c}^{\prime} \hat{\beta}_{\mathrm{L}}\right)_{\mathrm{F}}=\mathrm{b}_{1} \hat{\sigma}_{\epsilon}^{2}
$$

The expected mean square of the contrast $\underline{c}^{\prime} \hat{\beta}_{\mathrm{L}}$ can be determined as $\sigma_{\epsilon}^{2}+\left(\mathrm{b}_{2} / \mathrm{b}_{1}\right) \sigma_{\mathrm{a}}^{2}$. Using the estimates of the variance components, the estimate of the variance of $\underline{c}^{\prime} \hat{\underline{\beta}}_{L}$ is

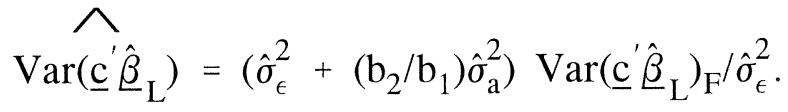

The variance in (3.8) is a linear combination of $\hat{\sigma}_{\epsilon}^{2}$ and $\hat{\sigma}_{\mathrm{a}}^{2}$, thus approximate degrees of freedom can be computed suing a method such as Satterthwaite's approximation (Milliken and Johnson (1984)). Confidence intervals and t-statistics can be computed using the estimate of $\underline{c^{\prime}} \underline{\beta}$, the estimated variance and the approximate degrees of freedom.

The numerator of the statistic to test $\mathrm{H}_{\mathrm{o}}: \underline{\mathrm{A}} \underline{\beta}=\underline{\mathrm{h}}$ vs $\mathrm{H}_{\mathrm{a}}: \underline{\mathrm{A}} \underline{\beta} \neq \underline{\mathrm{h}}$ where $\underline{\mathrm{A}} \underline{\beta}$ is a set of estimable functions for model (3.1) is

$$
\mathrm{SSH}_{0}=[\underline{\mathrm{A}} \underline{\hat{\beta}}-\underline{\mathrm{h}}]^{\prime}\left[[\underline{\mathrm{A}}, \underline{0}]\left[\begin{array}{ll}
\underline{\mathrm{X}} \underline{\mathrm{X}} & \underline{\mathrm{X}^{\prime}} \underline{\mathrm{Z}} \\
\underline{\mathrm{Z}^{\prime}} \underline{\mathrm{X}} & \underline{\mathrm{Z}^{\prime}} \underline{\mathrm{Z}}
\end{array}\right]^{\prime}\left[\begin{array}{l}
\underline{\mathrm{A}} \\
\underline{0}
\end{array}\right]\right]^{-}[\underline{\mathrm{A}} \underline{\hat{\beta}}-\underline{\mathrm{h}}]
$$

which is based on $\operatorname{Rank}(\underline{A})=r$ degrees of freedom. Under the conditions of $H_{0}$, the expected mean square of $\mathrm{SSH}_{0} / \mathrm{r}$ is $\sigma_{\epsilon}^{2}+\mathrm{b}_{3} \sigma_{\mathrm{a}}^{2}$. The estimates of the variance components are used to construct an estimate of $\sigma_{\epsilon}^{2}+b_{3} \sigma_{a}^{2}$ as $\hat{\sigma}_{\epsilon}^{2}+b_{3} \hat{\sigma}_{a}^{2}$ with $n$ approximate degrees of freedom (as determined by a method like Satterthwaite's Approximation). The test statistic is

$$
\mathrm{F}_{\mathrm{C}}=\frac{\mathrm{SSH}_{\mathrm{o}} / \mathrm{r}}{\hat{\sigma}_{\epsilon}^{2}+\mathrm{b}_{3} \hat{\sigma}_{\mathrm{a}}^{2}}
$$


which has approximate sampling distribution $\mathrm{F}_{(\mathrm{r}, \mathrm{m})}$. The noncentrality parameter for $\mathrm{F}_{\mathrm{c}}$ in $(3.10)$ is

$$
\lambda=[\underline{\mathrm{A}} \underline{\beta}-\underline{\mathrm{h}}]^{\prime}\left[[\underline{\mathrm{A}}, \underline{0}]\left[\begin{array}{ll}
\underline{X}^{1} \underline{\mathrm{X}} & \underline{\mathrm{X}}^{1} \underline{\mathrm{Z}} \\
\underline{Z}^{1} \underline{\mathrm{X}} & \underline{\mathrm{Z}}^{1} \underline{\mathrm{Z}}
\end{array}\right]^{-}\left[\begin{array}{c}
\mathrm{A}^{\prime} \\
\underline{0}
\end{array}\right]\right]^{-}[\underline{\mathrm{A}} \underline{\hat{\beta}}-\underline{\mathrm{h}}]
$$

\section{Comparisons and an Example}

An advantage of the mixed-model analysis is that estimable functions depend only on the design matrix $\underline{X}$ while for the non-mixed model analysis estimable functions depend on $[\underline{X}, \underline{Z}]$. Often, linear functions of $\underline{\beta}$ which should be estimable are deemed as non-estimable because of relationships between the columns of $\underline{X}$ and $\underline{Z}$.

Another advantage of the mixed-model analysis is that the estimate of $\underline{\beta}$ is a weighted least squares estimate which if the variance components were known provides the BLUE of $\underline{c} \underline{\beta}$ while the non-mixed models software provides the BLUE of $\underline{\underline{c}} \underline{\beta}$ when $\left(\underline{X}^{\prime} \underline{\hat{\Sigma}} \underline{X}\right)=\mathrm{f}\left(\sigma_{\epsilon}^{2}, \sigma_{\mathrm{a}}^{2}\right) \underline{X^{\prime}} \underline{X}$ and $\underline{X^{\prime}} \underline{\hat{\Sigma}} \mathrm{y}=\mathrm{f}\left(\sigma_{\epsilon}^{2}, \sigma_{\mathrm{a}}^{2}\right) \underline{X^{\prime}} \underline{y}$.

An advantage of non-mixed models analysis is the variance of an estimable function is a linear combination of the variances and the degrees of freedom can be approximated using procedures such as Satterthwaite's approximation to provide small sample properties. The variance of a linear estimable function from the mixed model analysis is not a linear function of the variances and thus its small sample size distribution is difficult to approximate.

The data in Table 4.1 is from Chapter 23 of Milliken and Johnson (1984). In this example, Machines are levels of a fixed effect while Persons are levels of a random effect. A model to describe the data is

$$
\mathrm{Y}_{\mathrm{ijk}}=\mu+\mathrm{M}_{\mathrm{i}}+\mathrm{P}_{\mathrm{j}}+(\mathrm{MP})_{\mathrm{ij}}+\epsilon_{\mathrm{ijk}}
$$

where $\mathrm{p}_{\mathrm{j}} \sim$ iid $\mathrm{N}\left(0, \sigma_{\mathrm{p}}^{2}\right),(\mathrm{MP})_{\mathrm{ij}} \sim$ iid $\mathrm{N}\left(0, \sigma_{\mathrm{MP}}^{2}\right)$ and $\epsilon_{\mathrm{ijk}} \sim$ iid $\mathrm{N}\left(0, \sigma_{\epsilon}^{2}\right)$.

Table 4.2 contains REML and Henderson's Method III (Method of moments using SAS ${ }^{\circledast}$ Proc GLM Type I sums of squares).

Table 4.3 contains estimates of the machine means using mixed models software (MM) and non-mixed models software (LS) with both REML and method of moments estimators of variance components. The LS estimates of the means are the same for both types of variance estimates, but the estimates of the standard errors depend on the type of variance estimation procedure. Table 4.4 contains estimates of differences between pairs of means and Table 4.5 contains the approximate degrees of freedom using method of moments estimators for each LS estimator.

For this data set, the mixed model and non-mixed model estimators are of similar magnitude with the mixed model variance slightly less than the corresponding nonmixed models variance. 
Table 4.1 Productivity Scores for Machine -- Person Example

\begin{tabular}{|c|c|c|c|c|}
\hline \multirow[b]{3}{*}{ Machine } & \multirow[b]{3}{*}{ Person } & \multicolumn{3}{|c|}{ Score } \\
\hline & & \multicolumn{3}{|c|}{ Unbalanced Case (Section 23.2) } \\
\hline & & 1 & 2 & 3 \\
\hline 1 & 1 & 52.0 & & \\
\hline 1 & 2 & 51.8 & 52.8 & \\
\hline 1 & 3 & 60.0 & & \\
\hline 1 & 4 & 51.1 & 52.3 & \\
\hline 1 & 5 & 50.9 & 51.8 & 51.4 \\
\hline 1 & 6 & 46.4 & 44.8 & 49.2 \\
\hline 2 & 1 & & & 64.0 \\
\hline 2 & 2 & 59.7 & 60.0 & 59.0 \\
\hline 2 & 3 & 68.6 & 65.8 & \\
\hline 2 & 4 & 63.2 & 62.8 & 62.2 \\
\hline 2 & 5 & 64.8 & 65.0 & \\
\hline 2 & 6 & 43.7 & 44.2 & 43.0 \\
\hline 3 & 1 & 67.5 & 67.2 & 66.9 \\
\hline 3 & 2 & 61.5 & 61.7 & 62.3 \\
\hline 3 & 3 & 70.8 & 70.6 & 71.0 \\
\hline 3 & 4 & 64.1 & 66.2 & 64.0 \\
\hline 3 & 5 & 72.1 & 72.0 & 71.1 \\
\hline 3 & 6 & 62.0 & 61.4 & 60.5 \\
\hline
\end{tabular}


Table 4.2 Estimates of Variance Components

$\begin{array}{lccc} & \text { Person } & \text { Mach } x \text { Person } & \text { Error } \\ \text { EM REML } & 22.456 & 14.234 & .871 \\ \text { Method 3 } & 21.707 & 17.079 & .873\end{array}$

Table 4.3 Estimates of Machine Means

MM (REML)

LS (REML)

MM (M3)

LS (M3)
$\mathrm{M}_{1}$ $52.354(2.491)$

$52.361(2.493)$

$52.354(2.560)$

$52.361(2.560)$
$\mathrm{M}_{2}$ $60.316(2.487)$ $60.339(2.489)$ $60.319(2.552)$ 60.339 (2.557)
$\mathrm{M}_{3}$ $66.272(2.483)$ $66.272(2.485)$ $66.272(2.552)$ $66.272(2.552)$

Table 4.4 Comparing Machines

MM (REML)
LS (REML)
MM (M3)
LS (M3)

MM (REML)

MM (M3)

$\mathrm{M}_{1}-\mathrm{M}_{2}$
$-7.962(2.215)$
$-7.978(2.217)$
$-7.967(2.419)$
$-7.978(2.420)$

$\mathrm{M}_{1}-\mathrm{M}_{3}$

$-13.918(2.209)$

$-13.911(2.212)$

$-13.918(2.415)$

$-13.911(2.415)$
$\mathrm{M}_{2}-\mathrm{M}_{3}$

$-5.956(2.206)$

$-5.933(2.208)$

$-5.953(2.411)$

$-5.933(2.411)$

\section{Table 4.5 Approx d.f. Method 3}

$\begin{array}{lr}\mathrm{M}_{1} & 9.16 \\ \mathrm{M}_{2} & 9.12 \\ \mathrm{M}_{3} & 9.05 \\ \mathrm{M}_{1}-\mathrm{M}_{2} & 10.12 \\ \mathrm{M}_{1}-\mathrm{M}_{3} & 9.98 \\ \mathrm{M}_{2}-\mathrm{M}_{3} & 10.04\end{array}$




\section{$\underline{\text { References }}$}

Henderson, C.R. (1984). Applications of Linear Models in Animal Breeding. University of Guelph, Canada.

McLean, Robert A., Sanders, William L., and Stroup, Walter W. (1991) "A Unified Approach to Mixed Linear Models,: The American Statistician, 45:54-64.

Milliken, George A. and Johnson, Dallas E. (1984). The Analysis of Messy Data, Vol. I: Designed Experiments. Von Nostrand Reinhold, New York.

SAS Technical report P-229, SAS/STAT software: Changes and Enhancements, Release 6.07, Cary, NC: SAS Institute Inc., 1992. 